\title{
New suture material for squint surgery
}

\author{
J.A. G. LANDERS \\ From the Department of Ophthalmology, Victoria Hospital, Kirkcaldy, Fife
}

The great number of different suture materials used for re-attaching the extraocular muscles reflects the problems which have been noted with so many. Perhaps the most worrying of these result from excessive inflammatory reaction in the region of the suture material. This paper describes the use of 6/o Ethiflex*.

\section{Clinical experience}

All operations were performed under general anaesthesia using a limbal approach to the insertions of the muscles, similar to that recently described by Fells (1971). The 6/o Ethiflex suture was then used in the standard manner employing a "whip" stitch on the edge of each muscle. At the moment the suture is presented with a Io-mm. taper-point needle. This is not ideal, but no problems, apart from the slightly increased pressure necessary to push them through the sclera, have been observed. The conjunctiva was closed with 6/o plain collagen.

Since May, 1971, this technique has been employed in 65 cases; six of these had undergone previous squint surgery and small granulomata were found at the site of the sutures (Figure). Two cases in which 6/o Ethiflex were used have been re-operated on after a period of 3 months and in neither was there evidence of granulomatous reaction. No clinical granuloma has been observed in any of the 65 cases, nor was there any other complication related to the suture material, or any limitation of abduction.

\section{Discussion}

Ethiflex is a non-reactive suture and is therefore ideal for strabismus work.

There was no inflammation in the region of the suture material either in the immediate postoperative period or during subsequent follow-up. This contrasts well with other suture materials, such as $6 / 0$ collagen, with which about 8 per cent. of cases show suture reactions (Smith, 1970).

Excessive reactivity results in increased scar tissue or granuloma formation. The former may cause limitation of abduction (Kennedy, 1970) and the latter necessitates excision. Should a needle accidentally penetrate the globe (Gottlieb and Castro, 1970) suture reactivity will increase the likelihood of serious intraocular inflammation.

The 6/o Ethiflex suture is of adequate tensile strength $\uparrow$ and can be readily tied without breaking. The present needle, designed for cardiovascular work, is not ideal, and would be better replaced with a spatulate needle which would minimize the risk of scleral perforation (Jervey, 1970; Reinecke, 197 I).

\section{Summary}

The use of 6/o Ethiflex suture material for squint surgery is described.

Received for publication November 30,1971

Address for reprints: J. A. G. Landers, F.R.C.S., ro4 Brougham Place, North Adelaide 5006, South Australia

*Braided polyester suture coated with polytetrafluoroethylene

†Average breaking load over a surgeon's knot $0.3 \mathrm{~kg}$ 


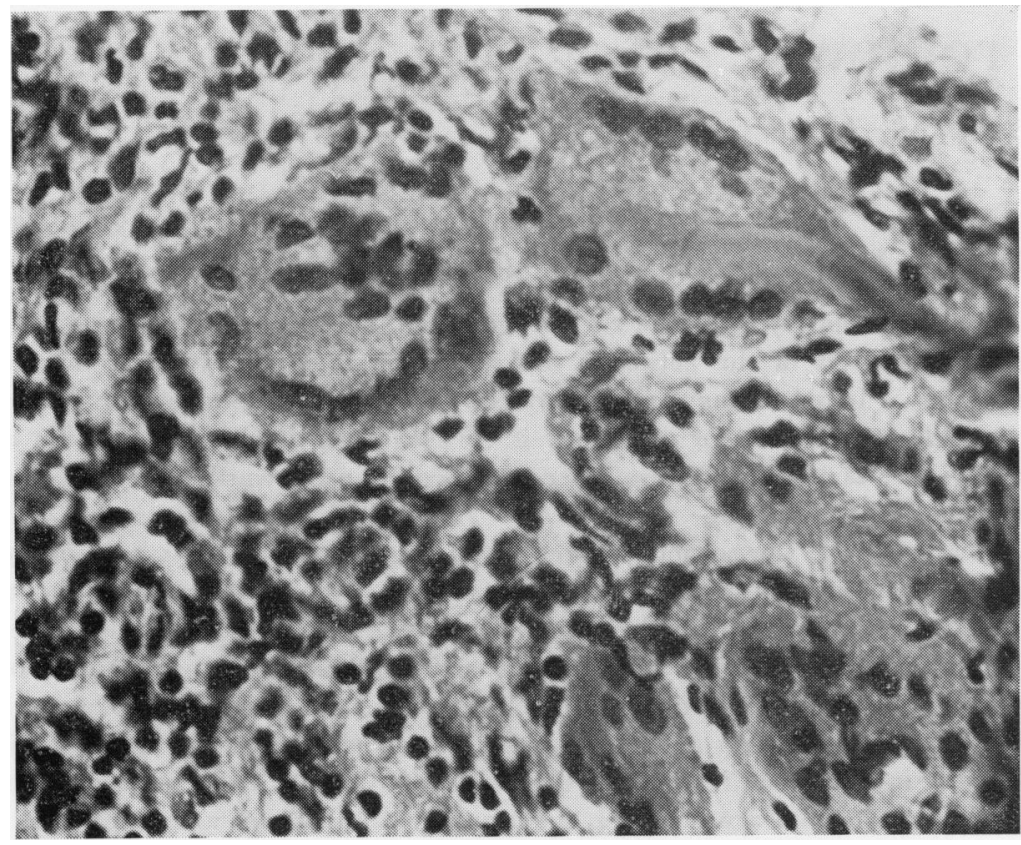

FIGURE Granuloma, showing plain absorbable material surrounded by giant cells. Haematoxylin and eosin $\times 160$

\section{References}

FELLS, P. (197I) Brit. F. Ophthal., 55, 550 gotTlieb, F., and CASTRO, J. L. (1970) Arch. Ophthal. (Chicago), 84, I5I JERVEY, E. D. (1970) Eye, Ear, Nose Thr. Monthly, 49, I 3 I KENNEDY, J. A. (1970) Arch. Ophthal. (Chicago), 84, 625 REINECKE, R. D. (I97I) Ibid., 86, 326 SMITH, A. (1970) Brit. J. Ophthal., 54, 522 